Supporting Information for

\title{
Transparent and Colorless Polyimides Containing Multiple Trifluoromethyl Groups as Gate Insulators for Flexible Organic Transistors with Superior Electrical Stability
}

Honggi Min,,${ }^{1, \dagger}$ Boseok Kang, ${ }^{2, \dagger}$ Yo Seob Shin, ${ }^{3}$ BongSoo Kim,, 4 , Seung Woo Lee,, 3 Jeong Ho Cho ${ }^{1, *}$

${ }^{1}$ Department of Chemical and Biomolecular Engineering, Yonsei University, Seoul 03722, Republic of Korea.

${ }^{2}$ SKKU Advanced Institute of Nanotechnology (SAINT) and Department of Nano Engineering, Sungkyunkwan University, Suwon, 16419, Republic of Korea.

${ }^{3}$ School of Chemical Engineering, Yeungnam University, Gyeongsan, 38541, Republic of Korea.

${ }^{4}$ Department of Chemistry, Ulsan National Institute of Science and Technology (UNIST), Ulsan 44919, Republic of Korea.

\section{AUTHOR INFORMATION}

Corresponding Authors

*Email: bongsoo@unist.ac.kr

*Email: leesw1212@ynu.ac.kr

*Email: jhcho94@yonsei.ac.kr

\section{Author Contributions}

${ }^{\dagger}$ H. Min and B. Kang contributed equally. 
a<smiles>CCN1C(=O)c2ccc(C(C)(C)C)cc2C1=O</smiles>

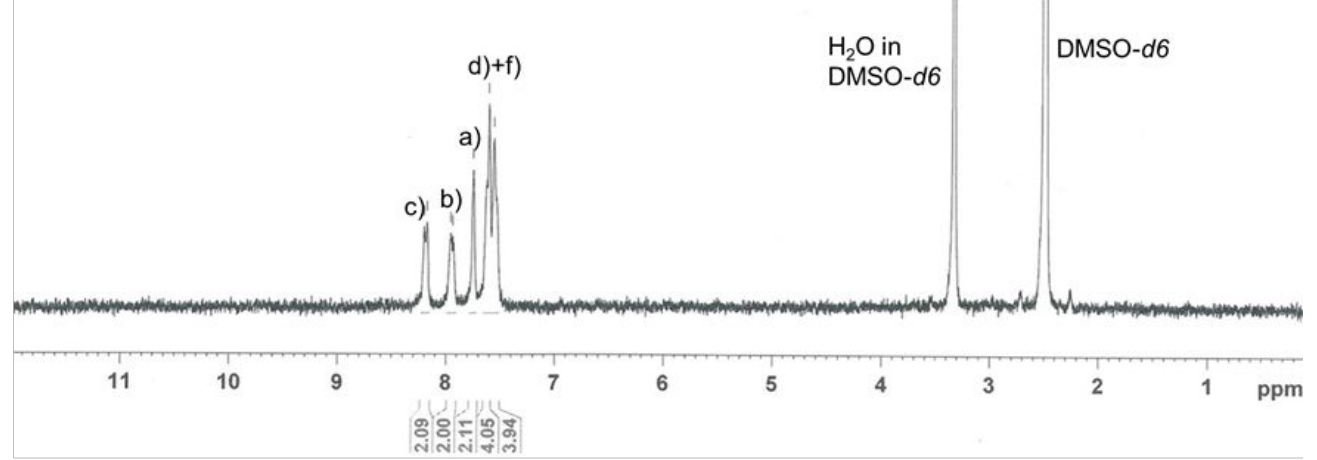

b
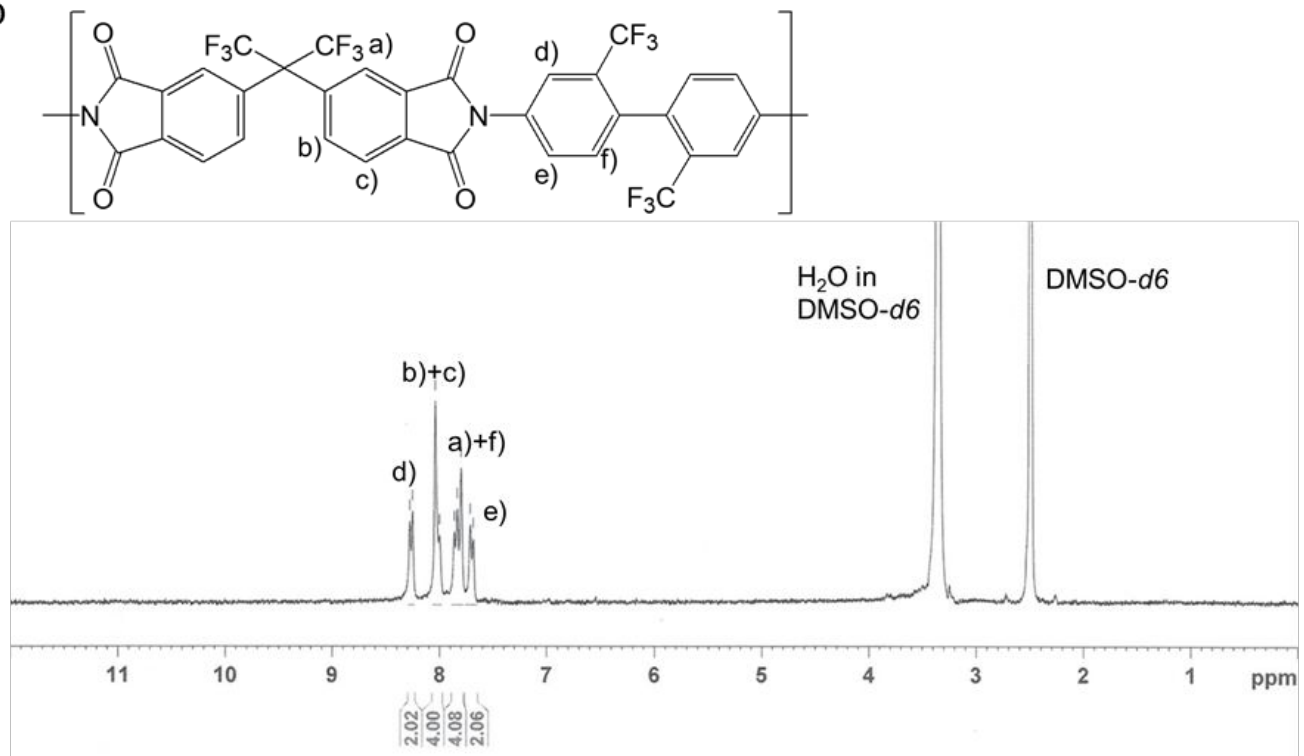

Figure S1. ${ }^{1} \mathrm{H}$ NMR spectra of (a) 6FDA-6FDAM-PI and (b) 6FDA-TFMB-PI.

Table S1. Solubility test results of the developed PI polymers for various solvents.

\begin{tabular}{|c|c|c|c|c|c|c|c|c|c|c|c|c|c|c|}
\hline & Toluene & DMAc & $m$-Cresol & THF & DMF & Xylene & AN & Benzene & $\mathrm{CF}$ & $\mathrm{CB}$ & DCB & Acetone & EA & BA \\
\hline $\begin{array}{c}\text { 6FDA- } \\
\text { 6FDA } \\
\text { M-PI }\end{array}$ & - & ++ & + & ++ & ++ & - & - & - & ++ & ++ & ++ & ++ & ++ & ++ \\
\hline $\begin{array}{c}\text { 6FDA- } \\
\text { TFMB- } \\
\text { PI }\end{array}$ & - & ++ & + & ++ & ++ & - & - & - & ++ & ++ & ++ & ++ & ++ & ++ \\
\hline
\end{tabular}

(-: insoluble, + : soluble after heating with sonication, ++ : soluble after sonication)

DMAc: dimethylacetamide, THF: tetrahydrofuran, DMF: $N, N$-dimethylformamide, AN: acetonitrile, CF: chloroform, CB: chlorobenzene, DCB: 1,2-dichlorobenzene, EA: ethyl acetate, BA: n-butyl acetate 

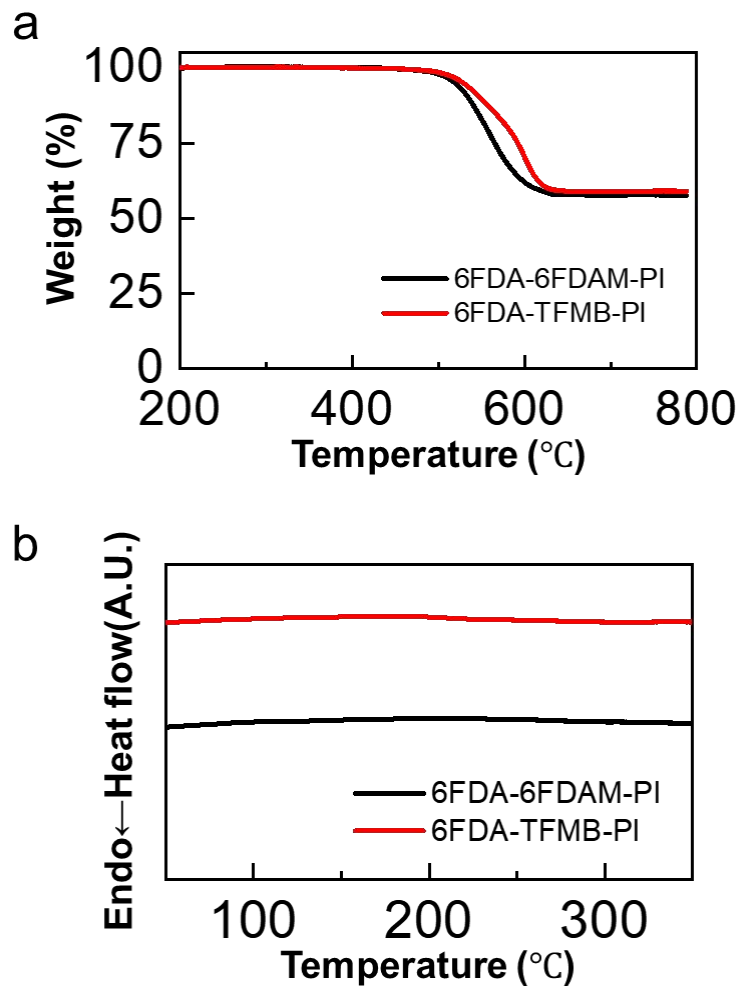

Figure S2. (a) TGA plots and (b) DSC thermograms of the synthesized PIs in a $\mathrm{N}_{2}$ atmosphere at a scan rate of $10{ }^{\circ} \mathrm{C} \mathrm{min}{ }^{-1}$.

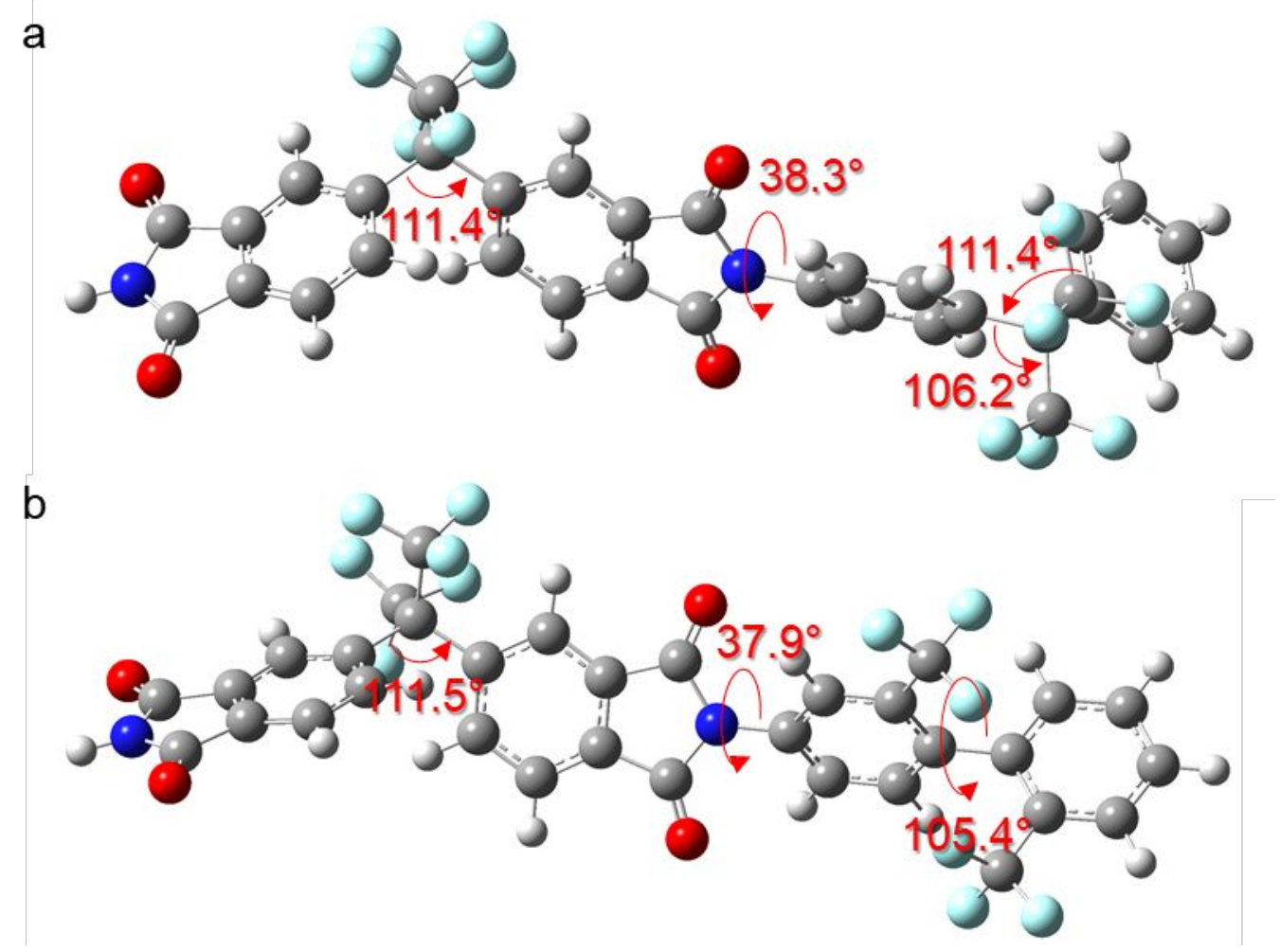

Figure S3. Optimized molecular geometries of the repeating units of (a) 6FDA-6FDAM-PI and (b) 6FDATFMB-PI by DFT calculations. 

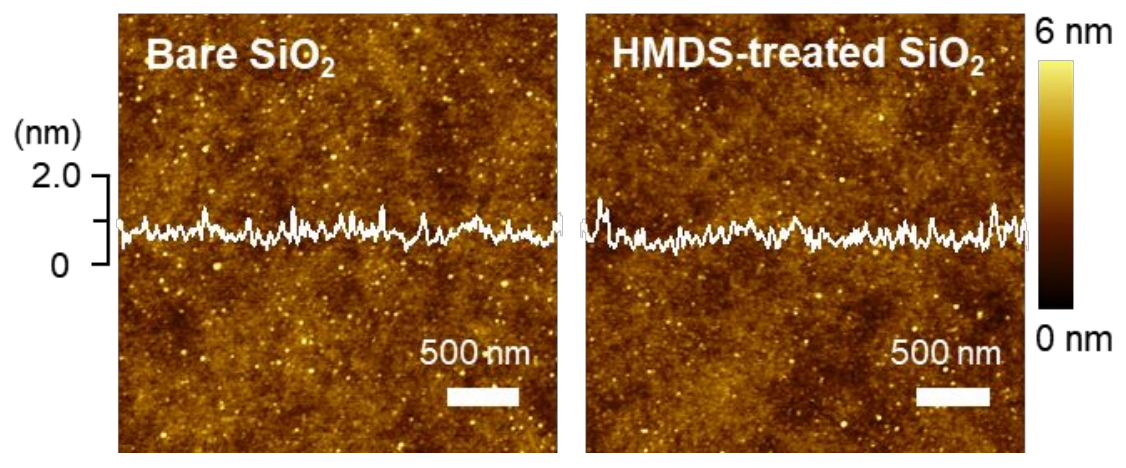

Figure S4. Surface topographies of bare and HMDS-treated $\mathrm{SiO}_{2}$ surfaces.
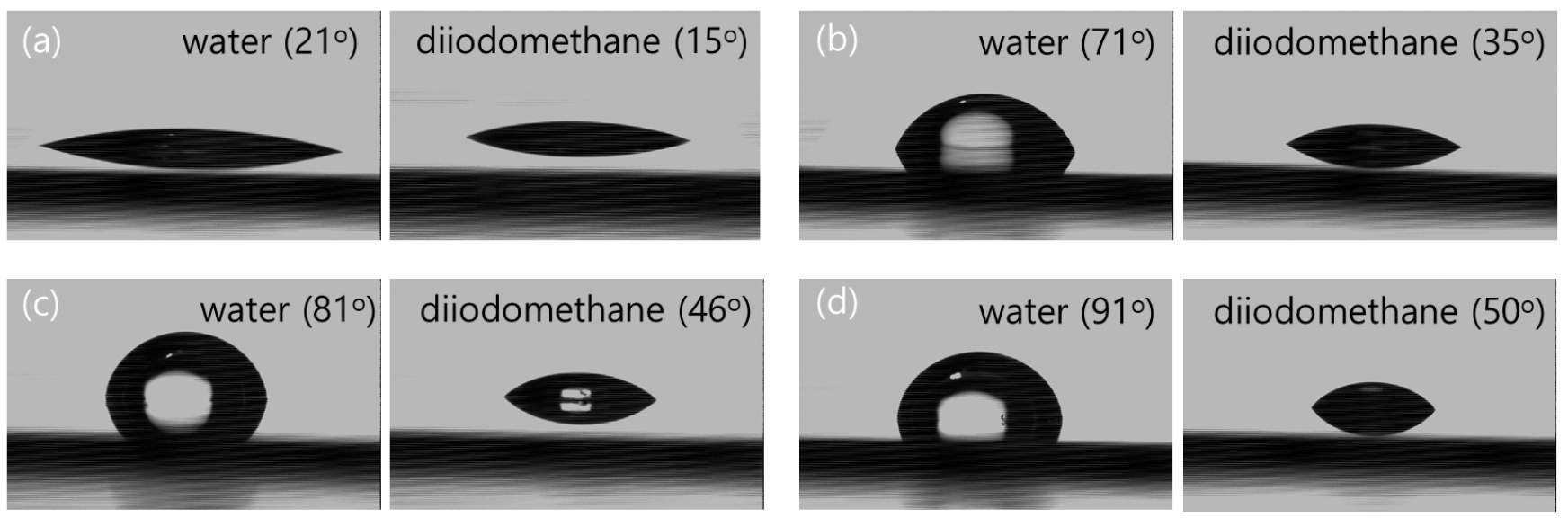

Figure S5. Contact angle measurements with water and diiodomethane for (a) bare $\mathrm{SiO}_{2}$, (b) $\mathrm{HMDS}$-treated $\mathrm{SiO}_{2}$, (c) 6FDA-6FDAM-PI, and (d) 6FDA-TFMB-PI substrates.

Table S2. Liquid contact angle and surface energy on various gate dielectrics.

\begin{tabular}{c|c|c|c}
\hline Gate dielectric & $\begin{array}{c}\text { Water contact angle } \\
\theta_{\text {water }}\left({ }^{\circ}\right.\end{array}$ & $\begin{array}{c}\text { Diiodomethane contact angle } \\
\theta_{\text {dii }}\left({ }^{\circ}\right)\end{array}$ & $\begin{array}{c}\text { Surface energy } \\
\left(\mathrm{mJ}^{-2}\right)\end{array}$ \\
\hline \hline Bare $\mathrm{SiO}_{2}$ & 21 & 15 & 70.06 \\
\hline HMDS-treated $\mathrm{SiO}_{2}$ & 71 & 35 & 44.04 \\
\hline 6FDA-6FDAM-PI & 84 & 46 & 36.76 \\
\hline 6FDA-TFMB-PI & 91 & 50 & 34.29 \\
\hline
\end{tabular}




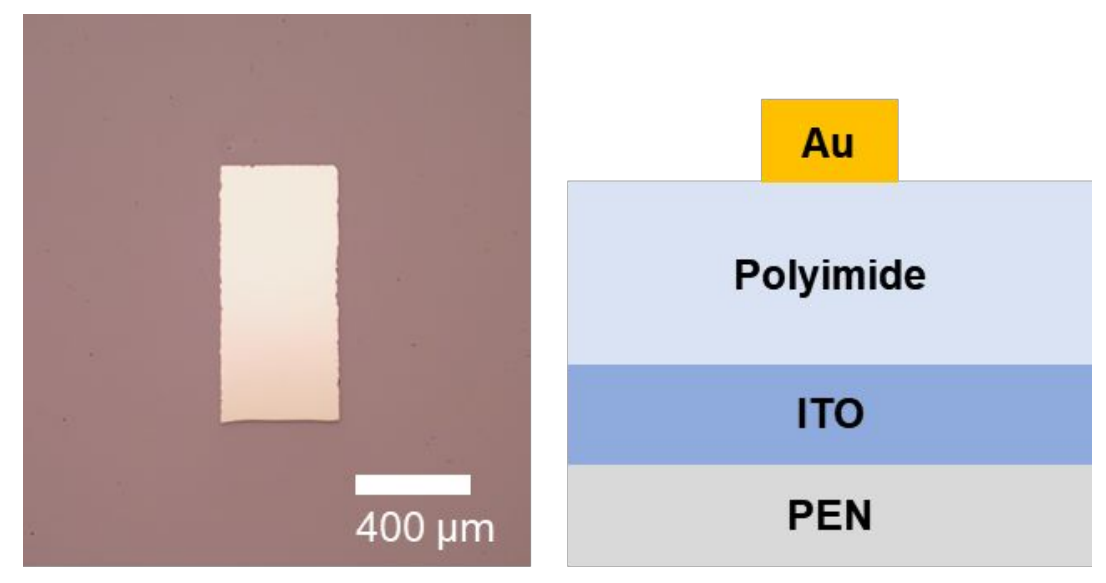

Figure S6. Optical microscopic image (left) and schematic device structure (right) of the metal-insulatormetal device for measuring capacitive properties of the synthesized PI materials.

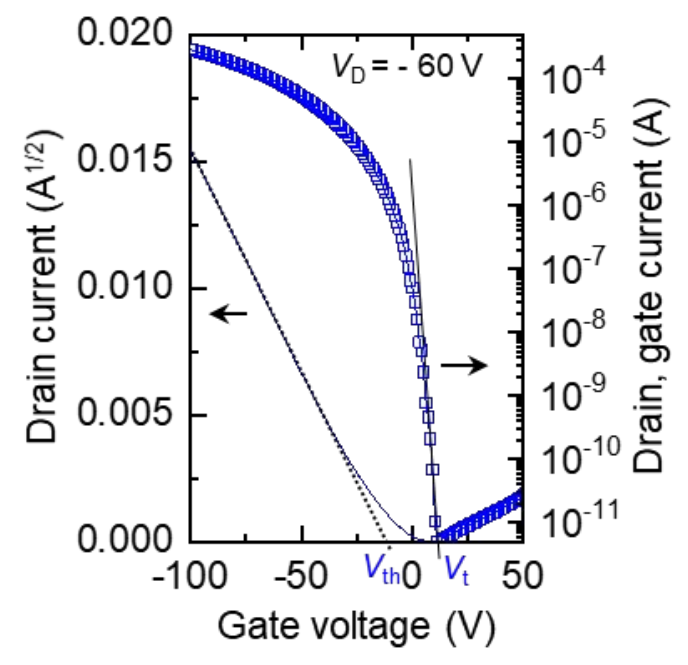

Figure S7. The determination of $V_{\mathrm{t}}$ and $V_{\mathrm{th}}$ voltages in a transfer curve.
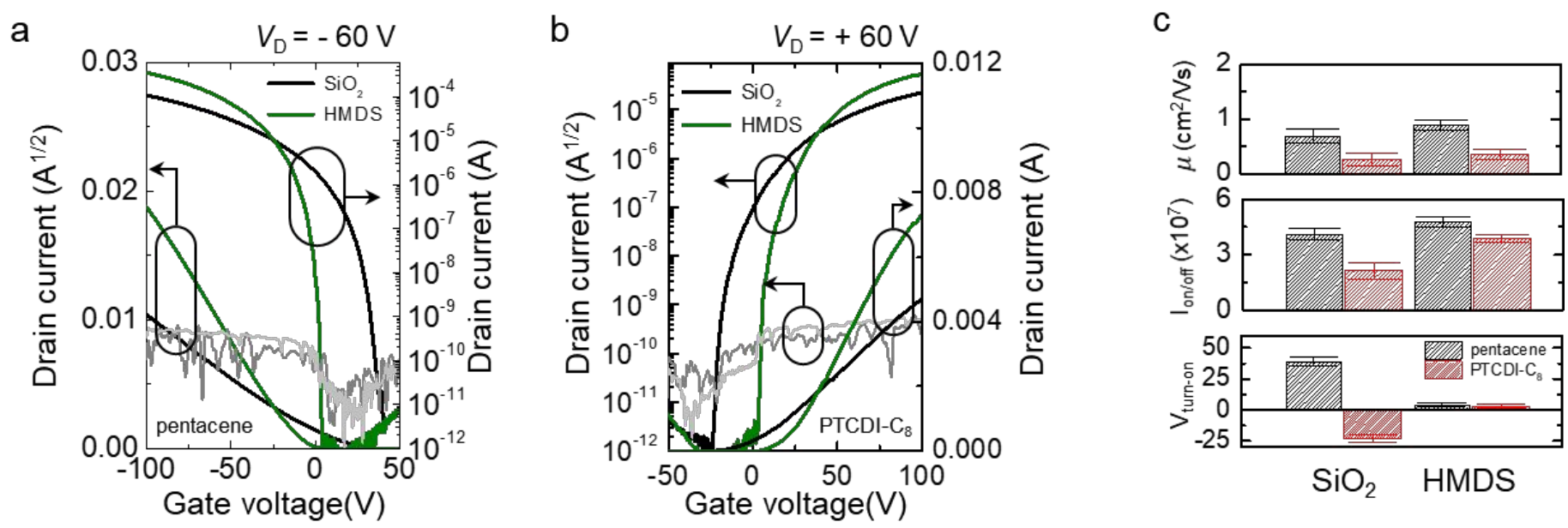

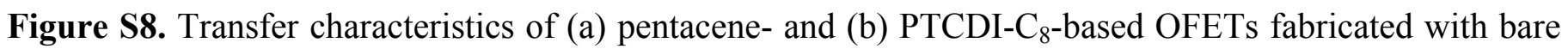
$\mathrm{SiO}_{2}$ and $\mathrm{HMDS}$-treated $\mathrm{SiO}_{2}$ gate dielectrics. Gray and dark gray lines indicate gate currents of OFETs with bare $\mathrm{SiO}_{2}$ and HMDS-treated $\mathrm{SiO}_{2}$, respectively. (c) Carrier mobility, ON-OFF current ratio, and turn-on voltage of devices estimated from transfer characteristics in (a) and (b). 

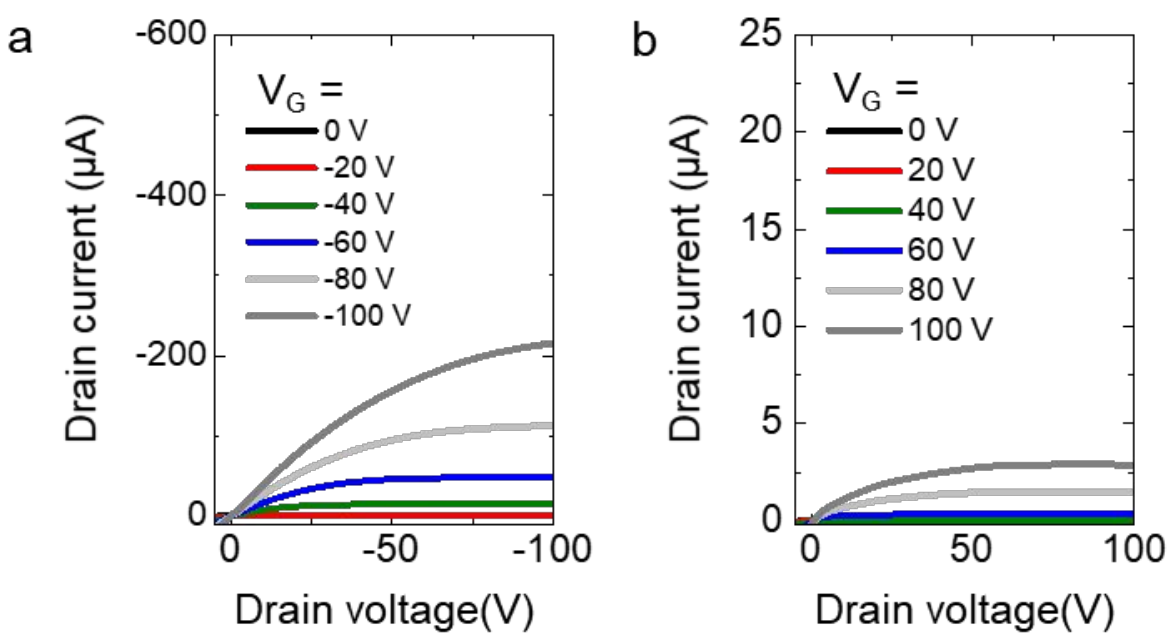

Figure S9. Output characteristics of (a) pentacene and (b) PTCDI-C8 OFETs fabricated with 6FDA-6FDAMPI.

a

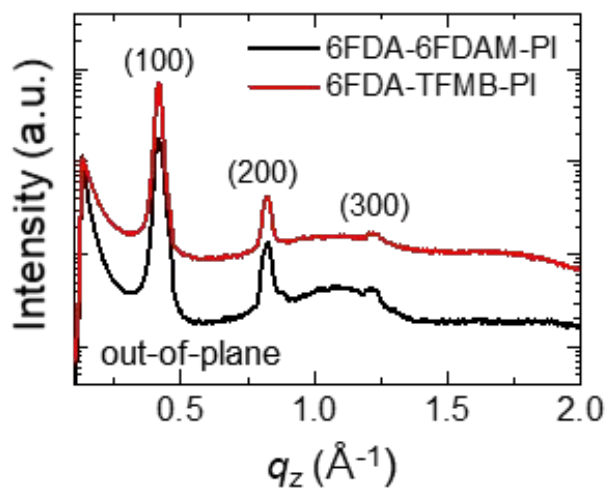

b

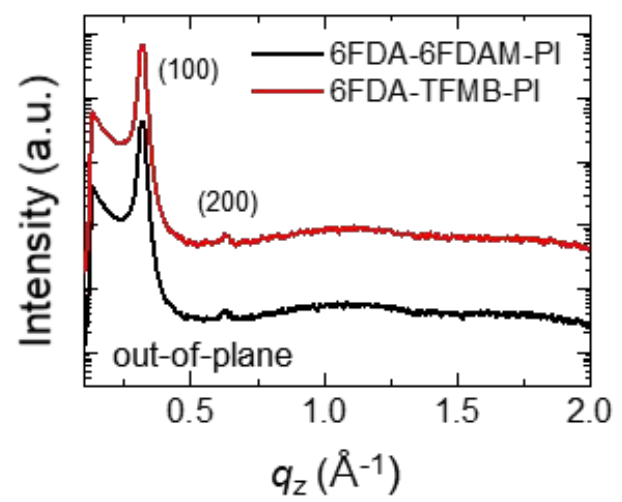

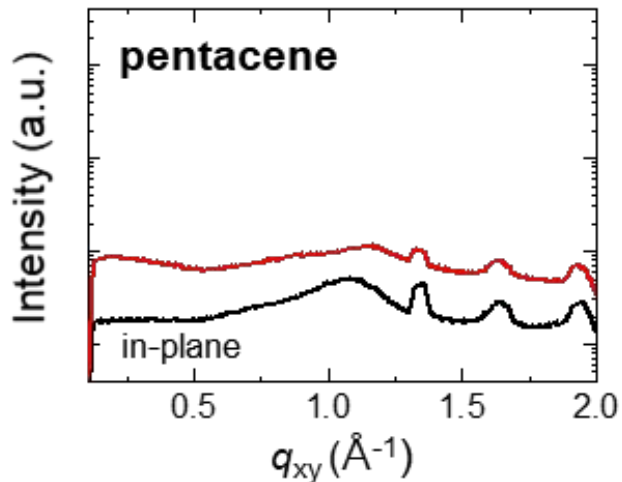

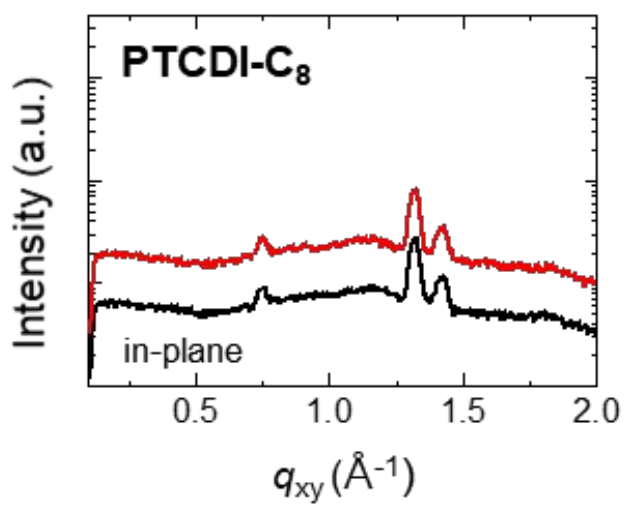

Figure S10. 2D-GIXD profiles along in-plane and out-of-plane directions of (a) pentacene and (b) PTCDIC8 films grown on fluorinated PI gate dielectrics. 
a

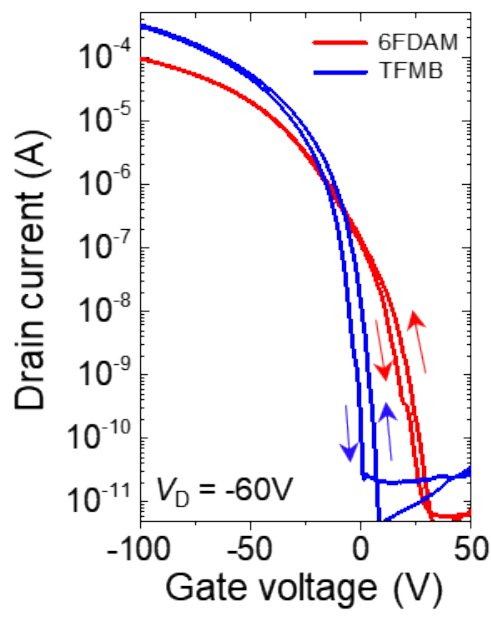

C

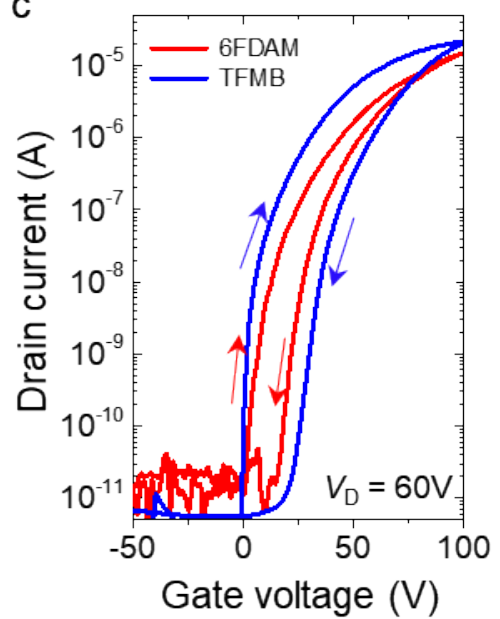

b

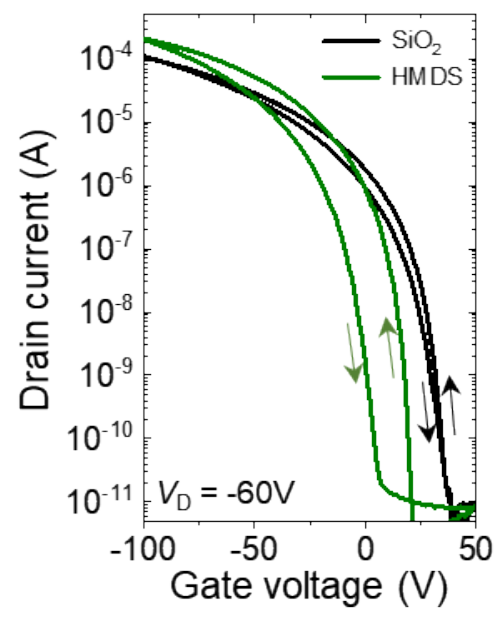

d

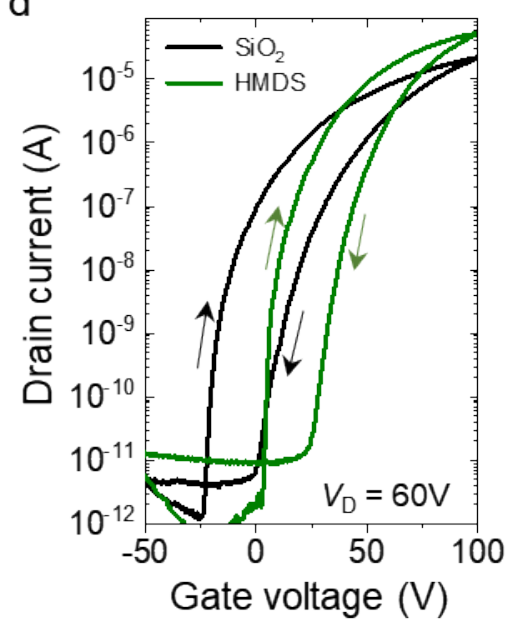

Figure S11. Hysteresis in transfer characteristics of petancene- and PTCDI- $\mathrm{C}_{8}$-based OFETs fabricated with $(a, c)$ 6FDA-6FDAM-PI or 6FDA-TFMB-PI gate dielectrics and $(b, d)$ bare or $\mathrm{HMDS}$-treated $\mathrm{SiO}_{2}$ gate dielectrics.

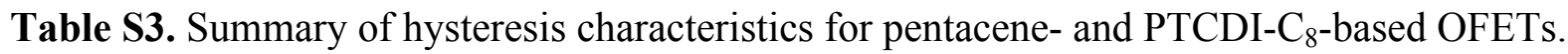

\begin{tabular}{|c|c|c|c|c|c|c|}
\hline & \multicolumn{3}{|c|}{ Pentacene } & \multicolumn{3}{|c|}{$\mathrm{PTCDI} \mathrm{C}_{8}$} \\
\hline & $V_{t}^{\text {Forward }}(\mathbf{V})$ & $V_{t}^{\text {Reverse }}(\mathrm{V})$ & $\Delta V_{\mathrm{t}}(\mathrm{V})$ & $V_{t}^{\text {Forward }}(\mathbf{V})$ & $V_{t}^{\text {Reverse }}(\mathrm{V})$ & $\Delta V_{\mathrm{t}}(\mathrm{V})$ \\
\hline 6FDA-6FDAM-PI & 33 & 30 & -3 & 1 & 15 & 14 \\
\hline 6FDA-TFMB-PI & 8 & 2 & -6 & -1 & 17 & 18 \\
\hline $\mathrm{SiO}_{2}$ & 40 & 38 & -2 & -25 & 0 & 25 \\
\hline HMDS & 22 & 8 & -14 & 3 & 22 & 19 \\
\hline
\end{tabular}



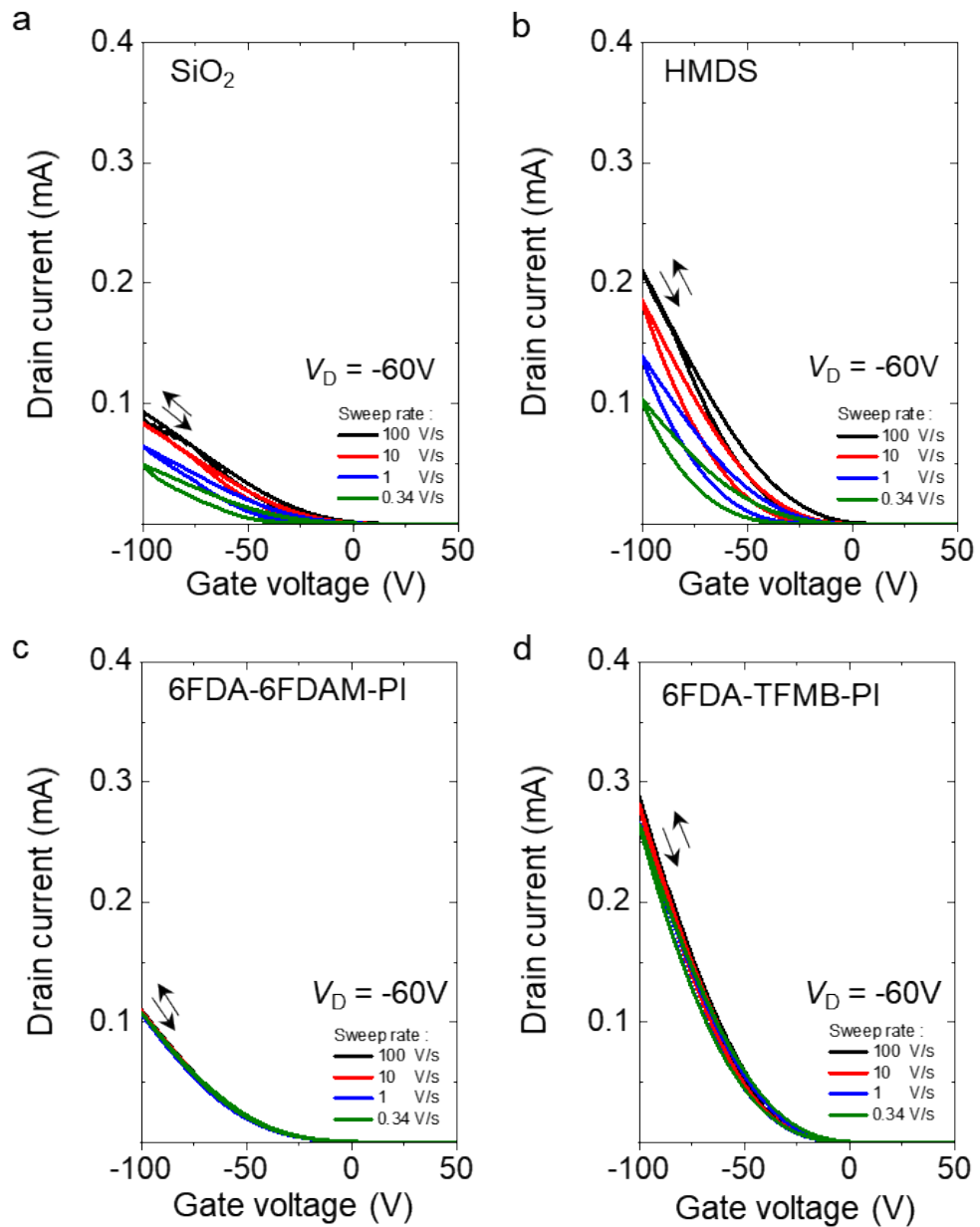

Figure S12. Transfer characteristics of pentacene OFETs with different GIs (a: bare $\mathrm{SiO}_{2}$, b: HMDS-treated $\mathrm{SiO}_{2}$, c: 6FDA-6FDAM-PI, and d: 6FDA-TFMB-PI) recorded at different $V_{\mathrm{G}}$ sweep rates. 

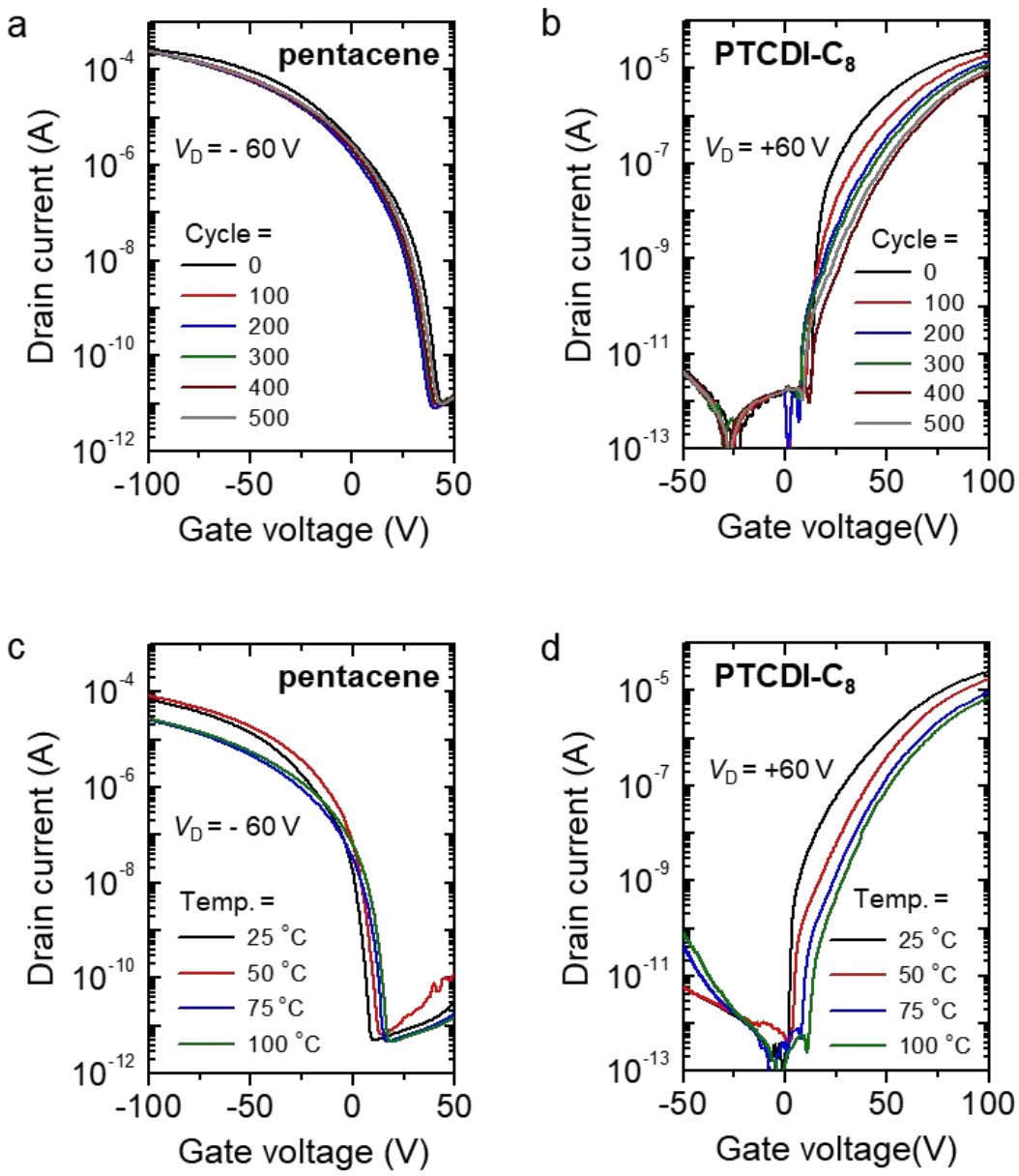

Figure S13. Transfer characteristics of pentacene and PTCDI-C $\mathrm{C}_{8}$ OFETs fabricated with 6FDA-TFMB-PI (a, b) after bending at $1 \%$ tensile strain and $(c, d)$ at elevated temperatures.
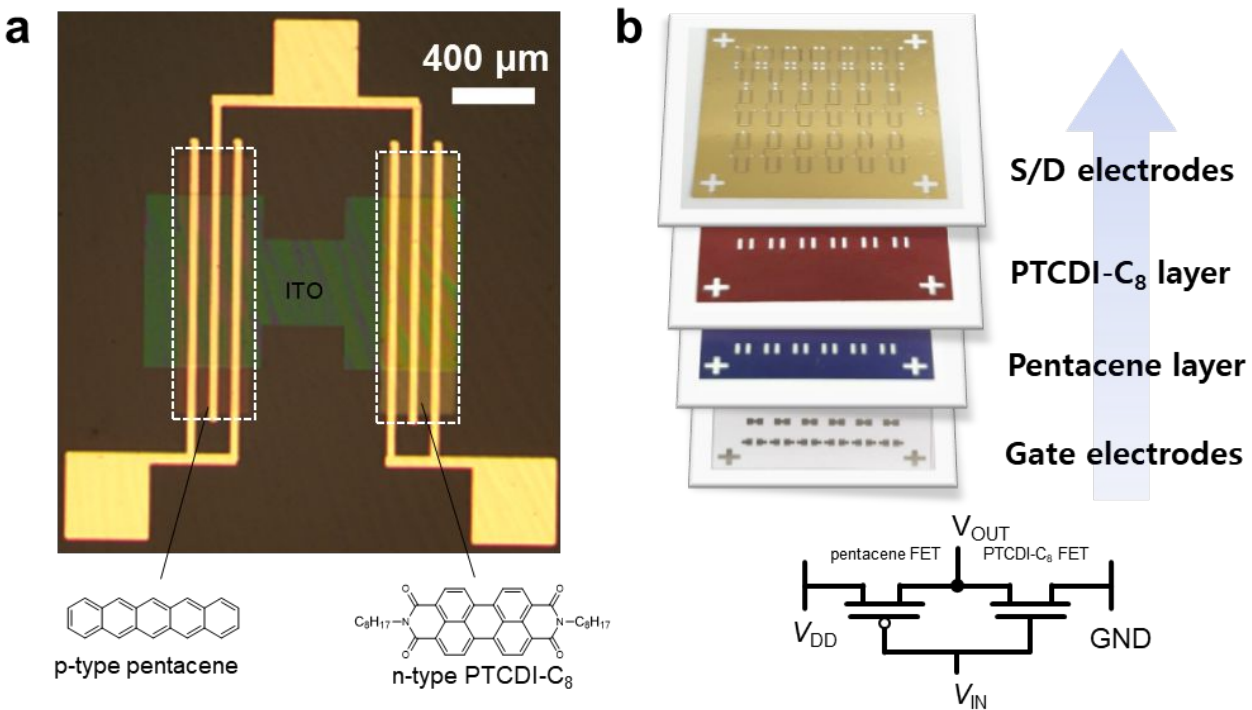

Figure S14. (a) Optical microscopy image and (b) fabrication steps of complementary inverter assembled using pentacene and PTCDI-C ${ }_{8}$ FETs. The bottom inset of figure $b$ shows a circuit diagram of the corresponding device. 